tormação de recursos humanos na saúde brasileira.

Delimitado às 14 categorias profissionais de saúde relacionadas n’kesolução $n^{\circ} 287$ do Conselho Naciønal de Saúde, de 8 de outubro de 1998, a metodologia de trabalho deste estudo priorizou a abordagem quantitatiy e qualitativa dos cursos de graduacão em Biomedicina, Ciências Biológicas, Educação Física, Enfermagem, Farmacia, Fisioterapia, Fonoaudiologia, Medicina, Medicina Veterinária, Nutrição,

\section{O pensamento de Durmeval Trigueiro Mendes para a educação e a universidade no Brasil}

MENDES, Durmeval Trigueiro. Ensaios sobre educação e universidade. [Textos selecionados por] Maria de Lourdes de 
Albuquerque Fávero, Jader de Medeiros Britto. Brasília: Instituto Nacional de Estudos e Pesquisas Educacionais Anísio Teixeira, 2006. $218 \mathrm{p}$.

Durmeval Trigueiro iniciou sua vida pública muito jovem, aos 24 anos (1951), exercendo o cargo de secretário de Educação da Prefeitura de Campina Grande, no Estado da Paraíba. Aos 26 anos (1954), o governador desse Estado convidou-o para dirigir a Secretaria de Educação e Cultura. Nessa função, organizou a Universidade da Paraíba, sendo escolhido pelo Conselho Universitário, em 1956, como seu primeiro reitor.

Em 1958, Anísio Teixeira, diretor do Instituto Nacional de Estudos Pedagógicos (Inep), convidou Durmeval para assumir o cargo de supervisor da Campanha de Educação Complementar. Por isso transferiu-se para o Rio de Janeiro, onde concentrou suas atividades profissionais. Indicado por Anísio Teixeira ao ministro da Educação, foi nomeado diretor do Ensino Superior do Ministério da Educação e Cultura (MEC), no período de 1961 a 1964. Pouco antes do golpe militar, passou a integrar o Conselho Federal de Educação (CFE), no qual permaneceu até setembro de 1969.

No regime militar, foi atingido pelo Ato Institucional $n^{\circ} 5$ (AI-5), que o aposentou compulsoriamente de todas as funções públicas. Durante cerca de dez anos não exerceu qualquer atividade pública. Os pesquisadores creditam tal fato ao seu posicionamento no CFE contrário à inserção nos currículos da disciplina Educação Moral e Cívica, proposta pelo então ministro da Guerra, Costa e Silva, ao ministro da Educação.

Somente em 1980 foi reintegrado como técnico do MEC e professor universitário. Nesse período, dedicou a maior parte de seu tempo aos mestrados de Educação do Instituto de Estudos Avançados em Educação da Fundação Getúlio Vargas (Iesae/FGV) e da PUC-RJ. Em sua trajetória, grande parte da sua produção centrou-se no mundo acadêmico e na universidade, em especial nos programas de pós-graduação em educação, nos quais atuou como professor, pesquisador e mestre de mestres. Sua marca mais profunda consistiu no fato de que vivia a fundo suas convicções, o que se expressa na vitalidade de suas propostas e na coerência entre o pensar e o agir.
A publicação "Durmeval Trigueiro Mendes - Ensaios sobre Educação e Universidade", organizada por Maria de Lourdes de Albuquerque Fávero e Jader de Medeiros Britto, reúne textos elaborados do educador e que foram publicados em periódicos, como a Revista Brasileira de Estudos Pedagógicos (RBEP), editada pelo Inep. Os textos contêm elementos das bases teóricas trabalhadas por Trigueiro Mendes em seus estudos e oferecem subsídios para se pensar a educação e a universidade no Brasil da década de 60 aos dias atuais.

O primeiro texto, "Realidade, experiência, criação", publicado na RBEP em 1973, propõe uma didática educacional que se apóie no conceito de educação em seu sentido mais profundo: educere, neste caso, significa deixar que o aluno use sua capacidade de criação. No estudo "Fenomenologia do processo educativo" (RBEP, 1974), Durmeval apresenta sua concepção de educação, compreendida como uma atividade criadora vinculada ao desenvolvimento que estimula a realização de um projeto pedagógico envolvendo a vontade e colaboração de todos os integrantes do grupo social. Reconhece que a educação não deve ser isolada e distanciada da realidade social.

Do período em que Durmeval atuou como diretor de Ensino Superior do MEC também foram selecionados alguns artigos. Em "Expansão do ensino superior no Brasil" (RBEP, 1967), o educador defende a tese de articular a expansão universitária com o desenvolvimento nacional. Propõe uma autonomia eficiente, a começar pela reformulação do ensino superior, com a criação de novo sistema de articulação entre governo e universidades, sobretudo quanto ao financiamento.

No texto "Governo da Universidade" (RBEP, 1967) o autor focaliza o diálogo universitário, bem como as responsabilidades do governo, reconhecendo a autonomia das instituições. Para ele, a defesa da universidade autônoma e democrática deve apoiar-se no princípio da gestão democrática em todas as instâncias: reitoria, centros, faculdades, escolas, institutos, departamentos, etc. Em "A Universidade e sua utopia" (RBEP, 1968), Durmeval reflete sobre a crise da universidade decorrente, segundo ele, de objetivos, funções e métodos. Para ele, se não houver mudanças nesses aspectos, nada mudará efetivamente. Defende a crítica como instrumento apropriado para combater a crise.

No estudo "Pesquisa e Ensino no Mercado de Educação" (RBEP, 1972), o educador 
apresenta a proposta inicial de um programa de pesquisa a ser desenvolvido pelo Iesae/ FGV, abrangendo três aspectos: a filosofia, a estratégia e a articulação com o ensino. A partir desses pressupostos, Durmeval propõe duas grandes linhas de pesquisa: uma motivada pelas necessidades educacionais do País e pelas eventuais encomendas das instituições e a outra demandada pelos programas dos cursos. A primeira estaria ligada à realidade dos fatos, enquanto a segunda se ordenaria de acordo com a lógica e o ritmo do currículo.

Na Revista de Cultura Vozes (1975), Durmeval Trigueiro publicou o texto "Desenvolvimento, tecnocracia e universidade", onde enfatiza a 'universidade pluralista' e questiona até onde as universidades do País, públicas e privadas, buscam este valor. Um dos últimos artigos produzido pelo educador e publicado logo após a sua morte também está no livro. "Anotações sobre o pensamento educacional no Brasil" (RBEP, 1987) traz uma análise independente sobre a emergência do ideário da Escola Nova na educação brasileira e seus principais protagonistas.

Além dos textos produzidos pelo educador, a publicação traz a sua biobibliografia, bem como a biografia de sua extensa produção acadêmico-científica. O trabalho resulta da pesquisa Durmeval Trigueiro Mendes e a questão da Universidade: 1960 a 1980, apoiada pelo CNPq.

Isabela Vargas Consultora - Inep órgão prestigiado de execução de campanho/s educacionais. Entre elas destacam-se a Campanha de Erradicação do Analfabetismo, a Campanha de Inquéritos e Levantamentos do Ensino Médio e Elementar (Cileme) e a Campanha do Livro Didático e Manuais de Ensino (Caldeme).

Anísio Teixeira criou, em 1955, o Centro Brasileiro de Pesquisas Edycacionais (CBPE) e os Centros Regionais/de Pesquisas Educacionais (CRPE). Seu/objetivo era possibilitar que a educação a escola e o magistério tivessem uma base científica a partir dos fundamentos das ciências sociais. Os centros contavam/com quadros intelectuais e técnicos que colocaram em prática a política naciona de educação progressista. Esta se orienlava em quatro diretrizes: o progresso das ciências sociais, a revolução industrial, o planejamento estratégico e o intercâmbio de conhecimentos e recursos humanos.

A publicaçã "Anísio Teixeira na Direção do Inep - Pfograma para a Reconstrução da Nação Brasileira: 1952-1964", organizada por Marta Maria de Araújo e Iria Brzezinski, busca identificar, em cada estado da Federação, os vínculos dos projetos, planos, experiências educacionais e reformas de ensino com o Programa de Reconstrução \#ducacional, pensado e executado por Ansisio Teixeira e colaboradores.

programa buscava pesquisar as condições culturais e as tendências de desenvolvimento de cada região brasileira, a fim de elaborar uma política educacional de essência científica. Os textos refletem essa regionalização Comecando pelo Suldo Brasil. 